\title{
THE PRICE OF LAND AND THE PROCESS OF EXPROPRIATION**
}

\author{
A Game Theoretic ANAlysis of the Dutch Situation
}

BY

MAARTEN C.W. JANSSEN, CHRISTIAN GERTH, LONNEKE JANSEN, MARINKA NIEHOFF*

\section{INTRODUCTION}

When the Dutch government wants to initiate a new public project, if often has to buy land from citizens. In cases like these, the citizen in question and the government face a situation of bilateral monopoly and the price the government has to pay in exchange for the ownership of the land depends on the bargaining power of the two agents. This paper focuses on the price the Dutch government pays to farmers in situations in which land of several farmers is bought in order to create a new public project (as a highway, or a recreation area - as explained in e.g. Visser, 1994).

Situations of bilateral monopoly between the government and a citizen in which the government wants to obtain (part of) the property of the citizen occur so often that the Dutch law specifies a procedure the government has to follow. The law also determines that in case of disagreement about the price of land, the court decides what the price of the land will be. Given this legal framework, a natural setting in which to analyze the bargaining problem is an asymmetric information model in which the government makes a number of sequential price offers to the farmers (whose private valuations are unknown to the government) before it goes to court.

Starting from Rubinstein (1982) there has been a rapidly growing non-cooperative game theoretic literature in which the offers (and counter-offers) of the bargaining parties are explicitly modelled as sequential moves. The literature that is closest to the situation we want to analyze in this paper has two features: (i) one party makes a finite number of sequential offers and the other party can only accept or reject these offers and (ii) the party that makes the offers is uninformed about the private valuation of the other party. Examples of this type of model include a durable good monopolist setting prices in a market in which it does not know the different consumers' willingness to pay (see e.g. Stokey, 1981

* The authors are all with the Erasmus University, Rotterdam. Please send correspondence to: M. Janssen, Department of Microeconomics, Erasmus University, P.O. Box 1738, 3000 DR Rotterdam, The Netherlands.

** This article springs from a paper that was written for the course Non-cooperative Game Theory and its Applications, Erasmus University, Spring 1994. We would like to thank two anonymous referees for their very helpful comments on an earlier draft of this paper. 
and Fudenberg and Tirole, 1991: pp. 400-416) and a union, making sequential wage offers to a firm whose profitability is unknown to the union (see e.g. Gibbons, 1992: pp. 218-224). Generally speaking, the above literature has yielded two relatively robust conclusions. First, most equilibria show a 'skimming property,' which means that high-valuation agents accept price offers before low-valuation agents. Second, some equilibria of these models exhibit what is called 'Coasian dynamics,' i.e. price offers decline over time. Another interesting property is that the monopoly power of the party that makes the offers disappears if it can make offers arbitrarily fast (see e.g. Gul et al., 1986). This property is sometimes referred to as the Coase conjecture. For a recent survey on bargaining with private information the reader is referred to Kennan and Wilson (1993).

The structure of the model that we will present is, from a mathematical point of view, equivalent to models that are studied in the above mentioned literature; in particular see Fudenberg and Tirole (1983) and Sobel and Takahashi (1983). The main difference is that in our case, the party who makes the offers (the government) is the buyer of the product (land), whereas in the earlier literature it is the seller (the monopolist or the union) who makes the offers. Consequently, as we will see, the skimming property and (in the case most commonly considered) the Coasian dynamics property are reversed.

Due to the fact that administrative procedures and the Dutch law determine a procedure that has to be followed our model is not subject to some of the criticisms that are launched against the non-cooperative bargaining literature. A first point of critique is that the outcome of the model is very sensitive to the assumed structure of offers and counter-offers. In many applications there seems to be no good reason to assume a particular structure of offers and counter-offers. We will see that in our case the structure of offers is determined by the Dutch law insisting that the government should have made enough attempts to come to a settlement by agreement. Second, in many models it is not clear why there is a finite number of bargaining rounds ( $c f$. the monopoly case) and/or what happens when the bargaining is over and no offer is accepted ( $c f$. the union case). As the Dutch law specifies that the government can go to court after having followed a specific administrative procedure that takes approximately three years, this critique also does not bear to our situation to the same degree. Third, as we will see, there are good reasons to believe that at the end of the bargaining process the government cannot make offers arbitrarily fast. This means that administrative procedures and the Dutch law can be regarded as commitment devices that make it possible for the government to benefit to some extent from its monopoly power. ${ }^{1}$ When discussing the legal framework and the way we have modelled the bargaining situation, we will discuss these points in more depth.

1 In this respect it might be interesting to note that a common point of view is that democratic governments have problems in making binding commitments (see e.g. Stiglitz, 1989). The case considered here might be regarded as a counterexample to this claim. 
Casual empiricism ${ }^{2}$ suggests two interesting phenomena about the bargaining process between the government and farmers in The Netherlands. First, almost all cases are solved via a settlement by agreement between the parties, i.e. the mere threat of a decision by court is enough to come to an agreement. Second, in some cases all farmers accept the first offer by the government; in other cases the government has to make several offers before all farmers accept. Both observations can be explained by our model. The conditions under which each of these situations (including the few situations that appear in court) applies is fully characterized.

The paper is organized as follows. Section 2 describes some institutional facts in which the bargaining process takes place. The legal rules can be interpreted as the rules of the game. Section 3 uses the information of section 2 to formulate the model. The game theoretic analysis is carried out in section 4. In this section we will also see to what extend our model exhibits properties as the skimming property, Coasian dynamics and the Coase conjecture. Section 5 summarizes the principal findings and concludes the paper. A formal proof of the main proposition is given in the Appendix.

\section{THE LEGAL FRAMEWORK ${ }^{3}$}

Before the government (read: local authorities, the city council, and so on) can bring the case to court three conditions have to be fulfilled: $(i)$ there must be a legally valid blue-print ('bestemmingsplan') of the area, (ii) an administrative procedure, resulting in a final offer, must have been followed and (iii) the government should have made serious attempts to obtain the ground via a settlement by agreement. We will describe each of these conditions in more detail below before describing the legal phase of the procedure itself.

The changing of the blue-print usually takes three to four years and can be divided in the following three steps. First, the plan must be made and published so that the opponents can bring in their petitions ('bezwaarschriften'). Second, the (possibly) revised plan must be published and another round of petitions follows. Finally, the definite plan must be approved so that it has legal force.

The administrative procedure takes approximately three years. The procedure starts with a topological sketch of the area and a conditional plan of expropriation. The plan is published and opponents can bring in their petitions. The (revised) expropriation plan is made and published and the final offer for the land owners is prepared. This offer is published in the Official Gazette ('Staatscourant'). If the owner does not accept the offer, the government can go to court and the offer is repeated at the citation.

2 Part of our observations are based on conversations with employees of 'recreatieschap Midden Delfland,' a group of civil servants who are actively engaged in the expropriation process.

3 The following is based on Berenschot (1970). 
While the administrative procedure takes place the government tries to obtain the land via a settlement by agreement ('minnelijke schikking'). The results of these informal negotiations are presented to the mayor. If an agreement has been reached this will be implemented. If no agreement is reached, the city and provincial councils discuss the issue and they bring out the final offer discussed in the previous paragraph. The time between the last (informal) offer and the final offer is approximately one year.

The process in court is relatively straightforward (from an economics point of view). At the start of the legal process, the owners of the land receive a summons to appear ('dagvaarding') and experts are asked to give an estimation of the price of the land. The process itself might take up to two or three years. The final sentence is based on the expert's report. The sentence determines the compensation payment (price) of the land. If the compensation payment is lower than or equal to the final offer that appeared in the Official Gazette, then the owner of the land is sentenced to pay the costs of the law suit, including the expenses of the experts. If the compensation payment the court determines is higher than the final offer by the government, then the government has to pay for the costs of the law suit. For simplicity, and for the simple fact that we rarely observe this happening in reality, we neglect the possibility of an appeal in cassation.

It should be noted that although the changing of the blue-print and the administrative procedure are legally completely independent of each other, usually they are started at the same moment in time. In most cases, the government initiates an informal procedure to settle by agreement. This informal procedure also takes place simultaneously with the official procedure and should have finished before the case can be brought to court.

\section{THE MODEL}

In the game theoretic analysis of the situation described in section 2 we assume that the administrative procedure and the informal procedure to get a settlement by agreement take place at the same moment in time. We will first present a basic model and subsequently look at an extended model. In the basic model, the government $G$ is assumed to make two price offers: a first offer $p_{f}$ and a final (or secondary) offer $p_{s}$. The first price offer can be considered as a simple representation of the informal negotiations described in the previous section. In the extension, we consider the effects of introducing many (informal) offers. An offer is assumed to be an overall price for the whole property. ${ }^{4}$ The farmers can only accept or reject the offer, but cannot make a counter-offer. If the offer is rejected, one year passes before a new (final) offer is prepared. When the second offer is

4 Alternatively, one could assume that the offer is a price per hectare. As the cost of the trial $C$ are independent of the size of the farm, this will create a difference between small and large farms. Apart from this difference, the qualitative results of the analysis below will continue to hold. 
also rejected, a trial is automatically started. The procedure that leads to the final blue-print of the area is not explicitly modelled. It is simply assumed that the blue-print has been prepared in the period the bargaining takes place and is valid in law when a trial is started.

The outcome of the trial is unknown to the government and the farmer and formally represented in the following simple way. A farmer wins (looses) the trial, if the compensation payment he gets in court is higher than (lower than or equal to) $p_{s}$. For simplicity, the outcome of the trial is represented by a move by nature. With a probability of $q$, nature chooses a high compensation payment, $p_{H}>p_{s}$, and with a probability of $1-q$ a low compensation payment, $p_{L} \leq p_{s}{ }^{5}$ Note that the farmer receives a lower price for his property in court than the last price offer by the government if $p_{L}<p_{s}$. The costs of the trial are denoted by $C$ and the party that loses the trial has to pay these costs.

The farmers' cost of giving up their land equals the discounted expected future income stream. The discount factor is denoted by $\delta$ and assumed to be identical for the two types of farmers and the government. The private valuation of their property depends on the type of farmer. In informal gatherings, civil servants (see footnote 2) usually distinguish two types of farmers, namely 'hobby' farmers and 'real' farmers. We simply follow this practice. A 'real' farmer expects to earn $x_{R}$ per year and the 'hobby' farmer expects to earn an income of $x_{H}$ per year. Assuming that the farmer could have earned $x_{R}$ or $x_{H}$, respectively, for many years ahead, the 'real' farmer's cost of giving up his land, denoted by $C_{R F}$, can be approximated by $x_{R} /(1-\delta)$ and the 'hobby' farmer's cost of giving up his land, which is denoted by $C_{H F}$, can be approximated by $x_{H} /(1-\delta)$. Following the same logic, the cost of giving up the land one year later is equal to $\delta x_{R} /(1-\delta)$, or $\delta C_{R F}$ and $\delta C_{H F}$ respectively. The percentage of 'real' farmers among the farmers whose land will be bought is given by $\alpha$. The present value of the land to the government is represented by $V$. It is assumed that $V>C_{R F}$, i.e., there are gains from trade.

The basic model, which is represented in extensive form in Figure 1, contains three stages. In stage 1, which lasts one year, the first offer is made and accepted or rejected. In stage 2, which also lasts one year, the second price offer is made and accepted or rejected. Finally, in stage 3, there is a possibility of a trial. A trial takes three years. The agents are assumed to maximize their discounted expected pay-offs, i.e. the farmers try to get the highest price possible, while the government attempts to get the lowest price possible. The model is common knowledge. The only thing the government does not know is to what type of farmer it makes a price offer.

5 A more realistic way of modelling the outcome of the trial is that the probability the government wins the trial positively depends on the last offer it made. This can be easily accomplished by representing nature's move by a continuous density function instead of by a discrete one. This, however, would only add technical complications. 


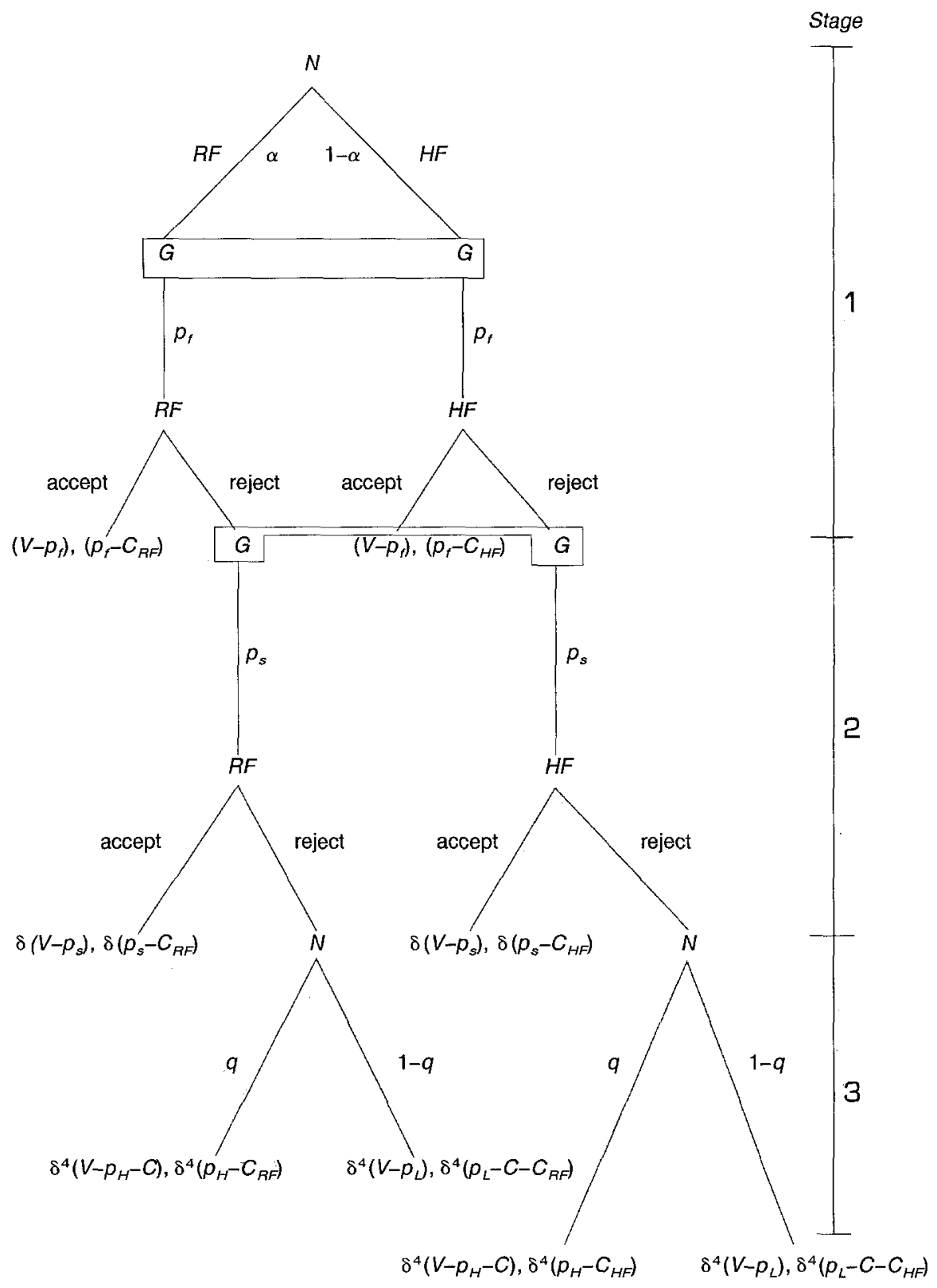

Figure 1 - Payoffs to Government and farmer, respectively

Apart from the informal negotiations that occur before the final offer is made, the basic model provides a relatively accurate description of the main ingredients 
of the procedure described in section 2 . In the extended model, the first price offer is replaced by an arbitrary number of informal offers; represented by $p_{f 1}, \ldots, p_{f n}$. In order to compare the pay-off of informal offer $p_{f j}, j=2, \ldots, n$, with $p_{f 1}$ we introduce a discount factor $\delta^{\prime}$, where $\left(\delta^{\prime}\right)^{n}=\delta$. The price offer $p_{f n}$ is the last informal offer the government makes. If this offer is rejected, one year passes before the second offer $p_{s}$ is made. The time between two subsequent informal offers can be arbitrarily fast. Formally, this means that $n$ can be very large and that $\delta^{\prime}$ will be close to 1 . In the next section we will show that the qualitative results of the basic model carry over to the extended model, which better describes the procedure given in section 2 .

Both the basic and the extended model can be interpreted in two ways. A first interpretation is that the government bargains with only one farmer, but it does not know what type of farmer ('real' or 'hobby') it bargains with. Here, $\alpha$ represents the government's prior belief of having to do with a 'real' farmer. Another interpretation is that the government bargains with many farmers at the same time, but that at any point in time it has to make (for example, for reasons of fairness or because of anti-discrimination laws) the same price offer to each farmer who has not yet accepted a previous offer. Here, $\alpha$ represents the fraction of 'real' farmers in the farmer population. In this latter interpretation the civil servants who bargain on behalf of the government cannot use information with respect to the type of farmer they are negotiating with, i.e. they cannot condition their price on the type of farmer, because they are forced to set the same price for everyone (see above).

\section{ANALYSIS}

In this section we will analyze which combination of price offers will be made and accepted. In order to do this we employ the concept of a perfect Bayes-Nash equilibrium. ${ }^{6}$ The formal analysis of the game is given in the Appendix. Here, we will discuss the results in a more informal way. The notion of a perfect BayesNash equilibrium adds two elements to the standard notion of a Nash equilibrium. First, the player's beliefs are updated using Bayes' rule (when applicable). In the context of the present model, this means that when making its second offer the government has more information (contained in the acceptance and/or rejection of the first offer) about the probability of having to do with a 'real' farmer than at the start of the game. It is optimal for the government to use this extra information. Second, the perfection requirement implies that at every information set the players' actions should be optimal (even at the ones that will not be

6 In the formal analysis players can choose mixed strategies. A mixed strategy in the present context can be best rationalized in the second interpretation of the model, i.e. the one in which the government bargains with many farmers at the same time. The mixed strategy can then be interpreted as the percentage of a particular type of farmer accepting the offer. 
reached given the strategies the players have chosen). This implies that the analysis of the game can start by analyzing the behaviour of the players at the last information sets. By looking at the last decision nodes of the 'real' and the 'hobby' farmer in the game tree in Figure 1 it becomes clear that the two types of farmers will accept $p_{s}$ if, and only if,

$$
p_{s}-C_{R F}>\delta^{3}\left[q\left(p_{H}-C_{R F}\right)+(1-q)\left(p_{L}-C_{R F}-C\right)\right]
$$

for the 'real' farmer and

$$
p_{s}-C_{H F}>\delta^{3}\left[q\left(p_{H}-C_{H F}\right)+(1-q)\left(p_{L}-C_{H F}-C\right)\right]
$$

for the 'hobby' farmer. If these inequalities are not satisfied, the farmers are better off, in expected terms, to reject the second price offer and go to court.

Looking at the last information set of the government reveals that the government will only make price offers $p_{s}$ that satisfy the following inequality:

$$
V-p_{s}>\delta^{3}\left[q\left(V-p_{H}-C\right)+(1-q)\left(V-p_{L}\right)\right]
$$

If this inequality is not satisfied the government is, in expected terms, better off by going to court. (As it is assumed that the government will immediately start a legal process once the second offer is rejected, it is implied that the R.H.S. of equation (3) is positive.)

Before stating the proposition, it is helpful to introduce the concepts of pooling and separating equilibrium. The equilibrium is pooling if the equilibrium price offers, denoted by $\left(p_{f}^{*}, p_{s}^{*}\right)$, are such that both types of farmers either accept $p_{f}^{*}$ or accept $p_{s}^{*}$, i.e. both types of farmers choose the same actions; the equilibrium is (fully) separating if the two types of farmers choose different actions, e.g. the hobby farmer accepts $p_{f}^{*}$ for sure and the 'real' farmer rejects $p_{f}^{*}$ for sure; the equilibrium is partially separating if the hobby farmer randomizes with positive probability between accepting $p_{f}^{*}$ and accepting $p_{s}^{*}$ and the real farmer accepts $p_{s}^{*}$ for sure.

Proposition. The unique perfect Bayes-Nash equilibrium of the game is pooling if $\alpha\left(V-C_{H F}\right)>\left(C_{R F}-C_{H F}\right)$ and it is (partially) separating if $\alpha\left(V-C_{H F}\right)<\left(C_{R F}-C_{H F}\right)$.

The proof of the proposition is given in the Appendix. Here, we will only provide the basic intuition of the proof and indicate some interesting features of the equilibrium price offers. In order to do so it is convenient to rewrite equations (1)-(3) as $\left(1^{\prime}\right)-\left(3^{\prime}\right)$ :

$$
\left.p_{s}>\delta^{3}\left[q\left(p_{H}-p_{L}+C\right)+p_{L}-C_{R F}-C\right)\right]+C_{R F}
$$




$$
\begin{aligned}
& \left.p_{s}>\delta^{3}\left[q\left(p_{H}-p_{L}+C\right)+p_{L}-C_{H F}-C\right)\right]+C_{H F} \\
& \left.p_{s}>\delta^{3}\left[q\left(p_{H}-p_{L}+C\right)+p_{L}-V\right)\right]+V
\end{aligned}
$$

For later reference we will define $p_{s}^{R}$ and $p_{s}^{H}$ as the R.H.S. of equations $\left(1^{\prime}\right)$ and (2'), respectively. As $V>C_{R F}>C_{H F}$, the R.H.S. of equation (3') is larger than $p_{s}^{R}$, which in turn is larger than $p_{s}^{H}$. This means that the government can always choose $p_{s}$ such that both types of farmers will accept and such that it is better off with the settlement by agreement than by going to court, i.e. there are gains from trade. Two other critical values are the lowest price offers a 'real' and a 'hobby' farmer would accept in the first stage. These values are denoted by $p_{f}^{R}\left(p_{s}\right)$ and $p_{f}^{H}\left(p_{s}\right)$ and are defined as:

$$
\begin{aligned}
& p_{f}^{R}\left(p_{s}\right)=\max \left\{\delta p_{s}^{R}+(1-\delta) C_{R F}, \delta p_{s}+(1-\delta) C_{R F}\right\} \\
& p_{f}^{H}\left(p_{s}\right)=\max \left\{\delta p_{s}^{H}+(1-\delta) C_{H F}, \delta p_{s}+(1-\delta) C_{H F}\right\}
\end{aligned}
$$

The intuition behind equations (4) and (5) is that a farmer will only accept the first price offer, if his expected pay-off of doing so is larger than the expected pay-off of either accepting the second offer or of going to court. Note that $p_{f}^{R}\left(p_{s}\right)$ and $p_{f}^{H}\left(p_{s}\right)$ depend on $p_{s}$.

One of the properties of related models is the skimming property referred to in the Introduction. In a dynamic monopoly setting, this property indicates that 'high-valuation' buyers accept price offers before 'low-valuation' buyers do. We will now check whether a similar property also holds in the context of our model. As the government is the buyer of the property and not the seller (as in the usual monopoly case) one would expect the skimming property to be reversed. The following observations with respect to the above four critical values are useful in this respect:

(i) $p_{s}^{R}>p_{s}^{H}$ (by comparing the R.H.S. of equations $\left(1^{\prime}\right)$ and $\left(2^{\prime}\right)$ );

(ii) $\forall p_{s}, p_{f}^{R}\left(p_{s}\right)>p_{f}^{H}\left(p_{s}\right)$ (by comparing equations (4) and (5) above);

The two observations together show that a reverse skimming property holds in our model: at any point in time it will not be the case that real farmers, which are the 'high-valuation' agents of our model, accepted a price offer, while hobby farmers did not.

By means of these two observations, the proof of the theorem identifies three possible equilibrium price offer configurations. Each of these equilibria is unique in a particular range of parameter values.

(a) $\left(p_{f}^{*}, p_{s}^{*}\right)=\left(\delta p_{s}^{R}+(1-\delta) C_{R F}, p_{s}^{R}\right)$, 
(b)

$$
\begin{aligned}
& \text { (b) } \quad\left(p_{f}^{*}, p_{s}^{*}\right)=\left(\delta p_{s}^{R}+(1-\delta) C_{H F}, p_{s}^{R}\right), \\
& \text { (c) } \quad\left(p_{f}^{*}, p_{s}^{*}\right)=\left(\delta p_{s}^{H}+(1-\delta) C_{H F}, p_{s}^{H}\right) .
\end{aligned}
$$

In case (a) both hobby farmers and real farmers accept the first offer. In case (b) all hobby farmers accept the first offer for sure and the real farmers accept the second offer for sure. In case (c) hobby farmers reject the first offer with a certain positive probability and accept the second price offer with the complement probability; the real farmers reject both offers for sure.

A second property of related models is the Coasian price dynamics property, which we also briefly mentioned in the Introduction. In a dynamic monopoly setting, this property says that a monopolist's price offers will decline over time. By investigating the equilibrium price offers in the above three cases we can check whether a similar property also holds in the context of our model. Note that for the same reason as above when discussing the skimming property one would expect our model to exhibit reverse Coasian price dynamics if any. It is easy to see that in all three cases price offers increase, i.e. $p_{f}^{*} \leq p_{s}^{*}$, if both $C_{R F} \leq p_{s}^{R}$ and $C_{H F} \leq p_{s}^{H}$. These last two inequalities in turn hold when the expected value of going to court for both real and hobby farmers, $q\left(p_{H}-C_{R F}\right)+(1-q)\left(p_{L}-C_{R F}-C\right)$ and $q\left(p_{H}-C_{H F}\right)+(1-q)\left(p_{L}-C_{H F}-C\right)$, respectively are nonnegative. This is the case most commonly focused upon in the literature on bargaining with asymmetric information. In our case, however, there is no particular reason to expect these expected values to be nonnegative and, correspondingly, $p_{f}^{*}$ may be larger than $p_{s}^{*}$.

Case $(a)$ is a pooling equilibrium, case $(b)$ is a separating equilibrium and case $(c)$ is a partially separating equilibrium. As the government makes the price offers, the government can choose which of the three types of equilibria will come about. In the Appendix it is shown that the government chooses to make offers such that the pooling equilibrium comes out if $\alpha\left(V-C_{H F}\right)>\left(C_{R F}-C_{H F}\right)$. In order to understand this conditions intuitively, let us look at the impact of the parameters $\alpha, V$ and $\left(C_{R F}-C_{H F}\right)$ in determining whether the equilibrium is pooling or separating. The main difference, from the government's point of view, between a separating and a pooling equilibrium is that in the former the government's first offer is lower than in the latter. Off-setting this advantage of a separating equilibrium is the fact that the discounted expected pay-off the government receives from obtaining the land from the 'real' farmers is larger under a pooling than under a separating equilibrium. Pulling in the direction of a separating equilibrium are then:

(i) A relatively low value of $\alpha$. The larger the fraction of the population of farmers (the 'hobby' farmers) that can be offered a relatively low first price offer, the more the government benefits from it. 
(ii) A relatively low value of $V$. The lower the subjective valuation of the government, the less the government is interested in obtaining all the land in the first stage.

(iii) A relatively large difference $C_{R F}-C_{H F}$. The larger this difference, the larger the difference in first price offers between potential pooling and separating equilibria.

The model also explains the observation that only a few cases end up in court. A case will end up in court if a farmer rejects both price offers. Above we have seen that in equilibrium $(a)$ and $(b)$ both types of farmers accept one of the two offers. This means that in these two equilibria no case will end up in court. In equilibrium $(c)$ the 'real' farmers, but not the 'hobby' farmers, reject both price offers. In the Appendix, we compare the pay-offs of equilibria $(b)$ and $(c)$. The calculations reveal that the government's pay-off of equilibrium $(c)$ is higher, if and only if, $\alpha$ is small. Recall that in the second interpretation of the model mentioned at the end of section $3, \alpha$ represents the percentage of 'real' farmers in the population of farmers. Thus, equilibrium $(c)$ will occur only if there are relatively few 'real' farmers and only these few farmers will reject both price offers (and only in this equilibrium configuration). This is why we claim that our model explains why only a few cases end up in court. The intuition for this result is the same as above: from the point of view of the government the advantage of case (c) over case $(b)$ is that the 'hobby' farmers receive a lower price. This advantage outweighs the disadvantage of a lower pay-off obtained from the expropriation of the 'real' farmers only if there are relatively few 'real' farmers, i.e. only if $\alpha$ is small.

Extensions of the model. In the extended model we consider a modification of the basic model in which the government can make many offers in the beginning of the bargaining process. The main aim of the extended model is to consider the impact of the possibility of making offers arbitrarily fast (in the informal negotiations) on the monopoly power of the government concerned. In the Introduction we mentioned that the Coase conjecture says that the monopoly power of a monopolist disappears in a dynamic environment if it can change prices arbitrarily fast. We will argue here that the Coase conjecture does not hold in our model. In order to show this, we will first provide the main intuition why the Coase conjecture holds in some existing models (see e.g. Gul et al., 1986). Subsequently, we will show what the impact is of allowing arbitrarily fast offers in the beginning of the bargaining process between the government and the farmers in our model. Finally, we will compare the intuition for our result with the Coase conjecture.

The main idea behind the Coase conjecture is nicely explained in Tirole (1988, pp. 80-87). He first considers a two-period monopoly model and shows that the monopolist charges lower prices in both periods compared to the standard single 
period monopoly model. The reason is that in the two-period model a profit-maximizing monopolist will flood the market in the second period by charging a relatively low price. However, as consumers can predict this behaviour, they will demand less in the first period and postpone some of their consumption until the second period. The resulting decrease in demand in the first period forces the monopolist to charge lower prices in the first period too. When there are (infinitely) many periods and when the length between the periods is very small, this problem takes on an extreme form: the monopolist looses all its monopoly power. The main reason for this phenomenon is that there are hardly any costs for the consumer to wait with his purchases until the next period when the length of a period becomes arbitrarily small.

Let us then turn to the extension of our model in which the government can make informal offers arbitrarily fast in the beginning of the bargaining process. For any number of informal offers $n$, the perfect equilibrium price offers $\left(p_{f 1}^{\prime}, \ldots, p_{f n}^{\prime}, p_{s}^{\prime}\right)$ can be determined by using backward induction. It is clear that by setting $p_{f n}^{\prime}$ and $p_{s}^{\prime}$ equal to the basic model's equilibrium values $p_{f}^{*}$ and $p_{s}^{*}$, respectively, the government can make at least as large a pay-off as it could in the basic model. The earlier price offers $p_{f 1}^{\prime}, \ldots, p_{f n-1}^{\prime}$ only provide a possibility to the government to make its pay-offs even larger. Thus, the monopoly power of the government does not diminish if we allow for arbitrarily fast offers during the informal negotiation process.

The reason why our model does not confirm the Coase conjecture is that the latter holds true only when $(i)$ the time lag between any two offers is arbitrary small and (ii) the bargaining process can go on indefinitely. The reason for the fact that both conditions do not hold in the situation we analyzed is that $(i)$ the government needs enough time (approximately one year) to prepare the offer that appears in the Official Gazette, i.e. the time lag between any two offers is not arbitrarily small and (ii) the Dutch law provides the government with the option of starting a legal process after three years, i.e. the bargaining process cannot go on indefinitely. These two conditions make it possible for the government to exploit some of its monopoly power.

\section{CONCLUSION}

In this paper we have analyzed the possibilities the Dutch government has to expropriate land from its citizens in order to initiate public projects. It turned out that the laws that apply to situations of expropriation in The Netherlands are so strict that they provide quite specific indications for the rules of the bargaining game between the two parties. The game theoretic analysis of the model that is presented provides an explanation for the observations that almost all cases of expropriation result in a settlement by agreement and that in some cases the first offer by the government is accepted, while in other cases several offers are made before all, or most, farmers accept. 


\section{APPENDIX}

Proof. The proof first proceeds by looking at the government's optimal behaviour in the last period. Let $\mu\left(p_{f}\right)$ be the government's assessment of the percentage of real farmers in the population of farmers that has not accepted the first price offer. It is clear that the government's optimal price offer in the second period is either $p_{s}^{R}$ or $p_{s}^{H}$, or randomizing over $p_{s}^{R}$ and $p_{s}^{H}$. The pay-off of choosing $p_{\mathrm{s}}=$ $p_{s}^{R}$ is $V-p_{s}^{R}$ and the pay-off of choosing $p_{s}=p_{s}^{H}$ is equal to $\left(1-\mu\left(p_{f}\right)\right)\left(V-p_{s}^{H}\right)$. Therefore, the optimal strategy for the government in the second period is given by:

$$
p_{s}=\left\{\begin{array}{l}
p_{s}^{R} \text { if } \mu\left(p_{f}\right)>\bar{\mu} \\
p_{s}^{H} \text { if } \mu\left(p_{f}\right)<\bar{\mu} \\
\text { any randomization between } p_{s}^{R} \text { and } p_{s}^{H} \text { if } \mu\left(p_{f}\right)=\bar{\mu}
\end{array}\right.
$$

where $\bar{\mu}\left(p_{s}^{R}-p_{s}^{H}\right) /\left(V-p_{s}^{H}\right)$. As $p_{f}^{R}\left(p_{s}\right)>p_{f}^{H}\left(p_{s}\right), \mu\left(p_{f}\right)$ can take on three values: (a) If both types of farmers accept $p_{f}$ for sure, $\mu\left(p_{f}\right)$ is indeterminate; $(b)$ if hobby farmers accept $p_{f}$ for sure and real farmers reject with a positive probability, $\mu\left(p_{f}\right)=1$; (c) hobby farmers randomize between accepting and rejecting the first offer and the real farmers reject it, $\alpha \leq \mu\left(p_{f}\right)<1$.

(a) Both types of farmers accept $p_{f}$ for sure if, and only if, $p_{f}>\delta$ $p_{s}^{R}+(1-\delta) C_{R F}$. Maximizing expected pay-offs means that the government should set $p_{f}$ as small as possible, which results in an expected pay-off of approximately $V-\delta p_{s}^{R}-(1-\delta) C_{R F}$.

(b) If $\mu\left(p_{f}\right)=1$, it is optimal for the government to set $p_{s}$ equal to $p_{s}^{R}$. In order for $\mu\left(p_{f}\right)$ to be equal to 1 , i.e. all hobby farmers accept $p_{f}$ for sure and real farmers reject $p_{f}$ with positive probability, $p_{f}$ should be larger than or equal to $\delta$ $p_{s}^{R}+(1-\delta) C_{H F}$. Maximizing pay-offs then implies that the government offers $\left(p_{f} P_{s}\right)=\left(\delta p_{s}^{R}+(1-\delta) C_{H F}, p_{s}^{R}\right) .{ }^{7}$ This combination of price offers gives the government an expected pay-off of $\alpha \delta\left(V-p_{s}^{R}\right)+(1-\alpha) \cdot\left(V-\delta p_{s}^{R}-(1-\delta) C_{H F}\right)$.

(c) In this case, we first concentrate on $\alpha<\mu\left(p_{f}\right)<1$, i.e. the 'hobby' farmers choose to accept $p_{f}$ with a probability strictly between 0 and 1 . Let this probability be denoted by $y\left(p_{f}\right)$. In order for the 'hobby' farmers to randomize, they have to be indifferent to either accepting $p_{f}$ or accepting $p_{s}$, i.e. the equilibrium values

7 Note that as $C_{R F}>C_{H F}$ the 'real' farmers will not accept $p_{f}$ Note also that when some real farmers reject the first offer with positive probability when the two offers $\left(p_{f}, p_{s}\right)$ are exactly equal to $\left(\delta p_{s}^{R}+(1-\delta) C_{R F}, p_{s}^{R}\right)$, the government gets a strictly smaller pay-off than in case $(a)$. So, this combination cannot be optimal. 
of $p_{f}$ and $p_{s}$, denoted by $p_{f}^{*}$ and $p_{s}^{*}$, respectively, have to be such that $p_{f}^{*}=\delta$ $p_{s}^{*}+(1-\delta) C_{H F}$. There are two generic subcases: $\mu\left(p_{f}\right)>\bar{\mu}$ and $\mu\left(p_{f}\right)<\bar{\mu}$. In the first case, the optimal $p_{s}$ is equal to $p_{s}^{R}$ and the separating equilibrium considered under $(b)$ comes about.

Let us then consider the other case. Here, the optimal $p_{s}$ equals $p_{s}^{H}$. In order for $\mu\left(p_{f}\right)$ to be smaller than $\bar{\mu}$, it must be the case that

$$
\mu\left(p_{f}\right)=\frac{\alpha}{\left(1-y\left(p_{f}\right)\right)(1-\alpha)+\alpha}<\bar{\mu},
$$

i.e. $y\left(p_{f}\right)<1-\alpha(1-\bar{\mu}) /(1-\alpha) \bar{\mu}$. A necessary condition to enable this is $\alpha<\bar{\mu}$. The expected pay-off of the government is then equal to $y(1-\alpha)$. $\left[V-\delta p_{s}^{H}-(1-\delta) C_{H F}\right]+\delta(1-y)(1-\alpha)\left[V-p_{s}^{H}\right]+\delta^{4} \alpha\left[q\left(V-p_{H}-C\right)+(1-q)\left(V-p_{L}\right)\right]$.

Finally, let us consider the case in which no farmer accepts $p_{f}$ i.e., the case $\mu\left(p_{f}\right)=\alpha$. Again we consider two subcases, $\alpha>\bar{\mu}$ and $\alpha<\bar{\mu}$, and show that for each of these two cases the expected pay-off of the government is smaller than the expected pay-off of case $(a)$, respectively, case $(c)$. If $\alpha>\mu$, the optimal $p_{s}$ equals $p_{s}^{R}$ and the expected pay-off of the government is $\delta\left(V-p_{s}^{R}\right)$. As $V>C_{H F}$ it is easily seen that this pay-off is smaller than $V-\delta p_{s}^{R}-(1-\delta) C_{H F}$, the pay-off under case $(a)$. If $\alpha<\bar{\mu}$, the optimal $p_{s}$ equals $p_{s}^{H}$ and the expected pay-off of the government is $\delta(1-\alpha)\left(V-p_{s}^{I I}\right)+\delta^{4} \alpha\left[q\left(V-p_{H}-C\right)+(1-q)\left(V-p_{L}\right)\right]$. Again, as $V>C_{H F}$, it is easy to see that this pay-off is smaller than the pay-off under case (c). Thus, the government will never set $p_{f}$ such that no farmer will accept it.

Case $(a)$ is a pooling situation, case $(b)$ is a separating situation and case $(c)$ is partially separating. A pooling equilibrium comes about if the pay-off of the government in such a situation is larger than the pay-off of the two (partially) separating situations. The pay-off under $(a)$ is larger than the pay-off under $(b)$ if

$$
V-\delta p_{s}^{R}-(1-\delta) C_{R F}>\alpha \delta\left(V-p_{s}^{R}\right)+(1-\alpha)\left(V-\delta p_{s}^{R}-(1-\delta) C_{H F}\right) .
$$

This inequality can be rewritten as $\alpha\left(V-C_{H F}\right)>\left(C_{R F}-C_{H F}\right)$. We still have to show that case $(c)$ does not yield a larger expected pay-off than case $(b)$ if $\alpha\left(V-C_{H F}\right)>\left(C_{R F}-C_{H F}\right)$. This is done by showing that the necessary condition for case (c) to be relevant, $\alpha<\bar{\mu}$, cannot be satisfied if $\alpha\left(V-C_{H F}\right)>\left(C_{R F}-C_{H F}\right)$. This claim is true if

$$
\bar{\mu} \equiv \frac{p_{s}^{R} x-p_{s}^{H} x}{V-p_{s}^{H} x}<\frac{V-C_{H F}}{C_{R F}-C_{H F}} .
$$

This is the case if $\left(1-\delta^{3}\right)\left(V-C_{H F}\right)<\left(V-p_{s}^{H}\right)$, which is equivalent to $V>q p_{H}+(1-q)\left(p_{L}-C\right)$. Due to the requirement that the R.H.S. of equation (3) is positive this inequality holds true. 
The same argument shows that a separating equilibrium comes about if $\alpha\left(V-C_{H F}\right)<\left(C_{R F}-C_{H F}\right)$. Unicity simply follows from the sequential nature of the game.

\section{REFERENCES}

Berenschot, B.W. (Ir. Buro), 1990, Grondverwerving in het belang van de volkshuisvesting en ruimtelijke ordening, Alphen aan den Rijn, Samson.

Fudenberg, D. and J. Tirole, 1983, 'Sequential Bargaining with Incomplete Information,' Review of Economic Studies, 50, pp. 221-247.

Fudenberg, D. and J. Tirole, 1991, Game Theory, Cambridge, MIT Press.

Gibbons, R., A Primer in Game Theory, 1992, Hemel-Hempstead, Harvester Wheatsheaf.

Gul, F., H. Sonnenschein and R. Wilson, 1986, 'Foundations of Dynamic Monopoly and the Coase Conjecture,' Journal of Economic Theory, 39, pp. 155-190.

Kennan, J. and R. Wilson, 1993, 'Bargaining with Private Information,' Journal of Economic Literature, 31, pp. 45-104.

Rubinstein, A., 1982, 'Perfect Equilibrium in a Bargaining Model,' Econometrica, 50, pp. 97-109.

Sobel, J. and I. Takahashi, 1983, 'A Multi-stage Model of Bargaining,' Review of Economic Studies, 50, pp. 411-426.

Stiglitz, J.E., 1989, 'On The Economic Role of the State,' in: A. Heertje (ed.), The Economic Role of the State, Oxford, Basil Blackwell.

Stokey, N., 1981, 'Rational Expectations and Durable Good Pricing,' Bell Journal of Economics, 12, pp. 112-128.

Tirole, J., 1988, The Theory of Industrial Organization, Cambridge, Mass., MIT Press.

Visser, E. de, 1994, 'Moerasplan kent veel bocrenleed,' De Volkskrant, April 6.

\section{Summary}

\section{THE PRICE OF LAND AND THE PROCESS OF EXPROPRIATION}

This paper applies a game theoretic model to situations in which the Dutch government expropriates land from some farmers in order to create a new public project. The model is a version of a finite period bargaining model with asymmetric information and one-sided offers. It is shown that the model can explain some casual observations as the fact that usually, but not always, the government and the farmers settle by agreement. 